\title{
A NATUREZA E DISTRIBUIÇÃO DAS OCORRÊNCIAS DE APATITA DA ÁREA IPIRÁ-PEDRAS ALTAS, NORDESTE DO ESTADO DA BAHIA
}

\author{
PLÍNIO MELCHIADES DE OLIVEIRA VEIGA* e PEDRO ANTÔNIO DE ALMEIDA COUTO*
}

\begin{abstract}
The geological studies developed by CPRM to the DNPM in the Apatita and Bahia If Projects in the Pedras Altas-Ipirá areas, Northeastern Bahia, identified belts of diopsidic rocks as the main depositories of apatite mineralization. Segments of tectonic plates related to Transamazonic and Guriense events border laterally the area in focus, delimitting zones of predominance of such calc-sillicated rocks.

It is admitted the interaction of two genetic processes in the formation of apatite: 1) from an old sedimentary origin of calc-pelitic nature, in disseminated form, and 2) by later metasssomatic processes, related to the emplacement of syenitic pegmatites which cut the calc-sillicatic sequences and constitute remobilized zones with concentrations in the form of lodes, lenses and pods. It is suggested, to the first case, supplementary investigations in order to set up its economic importance.
\end{abstract}

INTRODUÇ̃̃o As ocorrências de apatita conhecidas na área Ipirá-Pedras Altas, nordeste do Estado da Bahia, distribuídas segundo um marcante controle litológico, motivaram a criação do Projeto Apatita, executado pela CPRM para o DNPM durante o período $1970 / 1971$.

Desenvolveram-se estudos de mapeamento geológico na escala de reconhecimento regional 1:500 000 até escalas de detalhe 1:10000 e 1:400 acompanhados de prospecção geofísica, cintilometria terrestre, além de escavaçðes de poços e trincheiras, objetivando avaliar a potencialidade das ocorrências de apatita da área em causa.

Concluiu-se que a reserva estimada para as ocorrências estudadas, até uma profundidade média de $10 \mathrm{~m}$, não ultrapassaria a $10000 \mathrm{t}$, considerando-se tipos remobilizados, concentrações $30 \%$ de apatita e teor de $40 \%$ em $\mathrm{P}_{2} \mathrm{O}_{s}$, ressaltando-se que até a profundidade investigada as concentraçð̃es tendem a um empobrecimento. Soluçôes ricas em fósforo e flúor, relacionadas a uma fase pegmatítica de composição sienítica, interagiram com as rochas piroxênicas (diopsiditos), sendo o principal fator de enriquecimento desses depósitos de apatita.

A partir da evolução dos conhecimentos geológicos e com base nos trabalhos básicos, recentemente executados pela CPRM para o DNPM, bem como nas investigaçðes adicionais do Instituto de Geociências da UFBA, apresentam-se elementos complementares sobre o comportamento, a natureza e a perspectiva de economicidade das mineralizaç̃̃es de apatita dos tipos remobilizado e disseminado existentes na faixa de rochas calcossilicáticas.

A importância de mineralizações disseminadas de apatita nos diopsiditos deve ser definida conșiderandose a possibilidade de essas rochas representarem antigas sequêencias sedimentares pelito-carbonáticas. Teores da ordem de 7,5\% de $\mathrm{P}_{2} \mathrm{O}_{5}$, caso sejam constatados, poderão viabilizar projetos para a produção de superfosfa- to tendo em vista a ampla distribuição de rochas calcossilicáticas no nordeste da Bahia.

GEOLOGIA REGIONAL As rochas piroxênicas ricas em diopsídio, as principais hospedeiras das ocorrências de apatita desta parte do nordeste da Bahia, estão situadas entre o lineamento estrutural de direção noroeste-sudeste que passa em Riachão de Jacuípe, considerado como um segmento de placa retrabalhado no ciclo Transamazônico (Neves et. al., 1980), e a feição estrutural que passa nas imediaçס̃es de Itaberaba, admitida como uma porção da placa relacionada ao evento guriense, com idade superior a 2700 m.a. (Seixas et. al., 1975).

A sucessão estratigráfica da área em questão, configurada no mapa geológico na escala 1:500 000 (Fig. 1), está representada regionalmente por rochas pertencentes aos complexos Granulítico e Metamórfico-Migmatítico, os quais estão em geral associados aos níveis individualizados de diopsiditos, anfibolitos, serpentinitos e quartzitos, além de rochas graníticas, estas com aparente caráter intrusivo, constituindo corpos irregulares ricos em biotita. Este conjunto litológico apresentase parcialmente coberto por sedimentos inconsolidados, provavelmente de idade Terciária, denominados Formação Capim Grosso (Neves e Feitosa, 1969).

COMPLEXO GRANULITICO - PRÉ-CAMBRIANO Piroxênio - granulito, charnockitos, diatexitos, biotita e hornblenda gnaisses, localmente com textura augen, calcossilicáticas, quartzitos, anfibolitos e biotita granitos são os tipos litológicos mais comuns dessa unidade estratigráfica.

Os piroxênios granulitos apresentam contatos.gradativos com os metatexitos e estão comumente intercalados com charnockitos ácidos e intermediários, os quais se associam com augen-gnaisses e biotita, hornblenda gnaisses. Localmente, podem apresentar estrutura estromatolítica, nebulítica e schlieren, com enclaves de composição básica. Quartzo, plagioclásio, ortopi- 


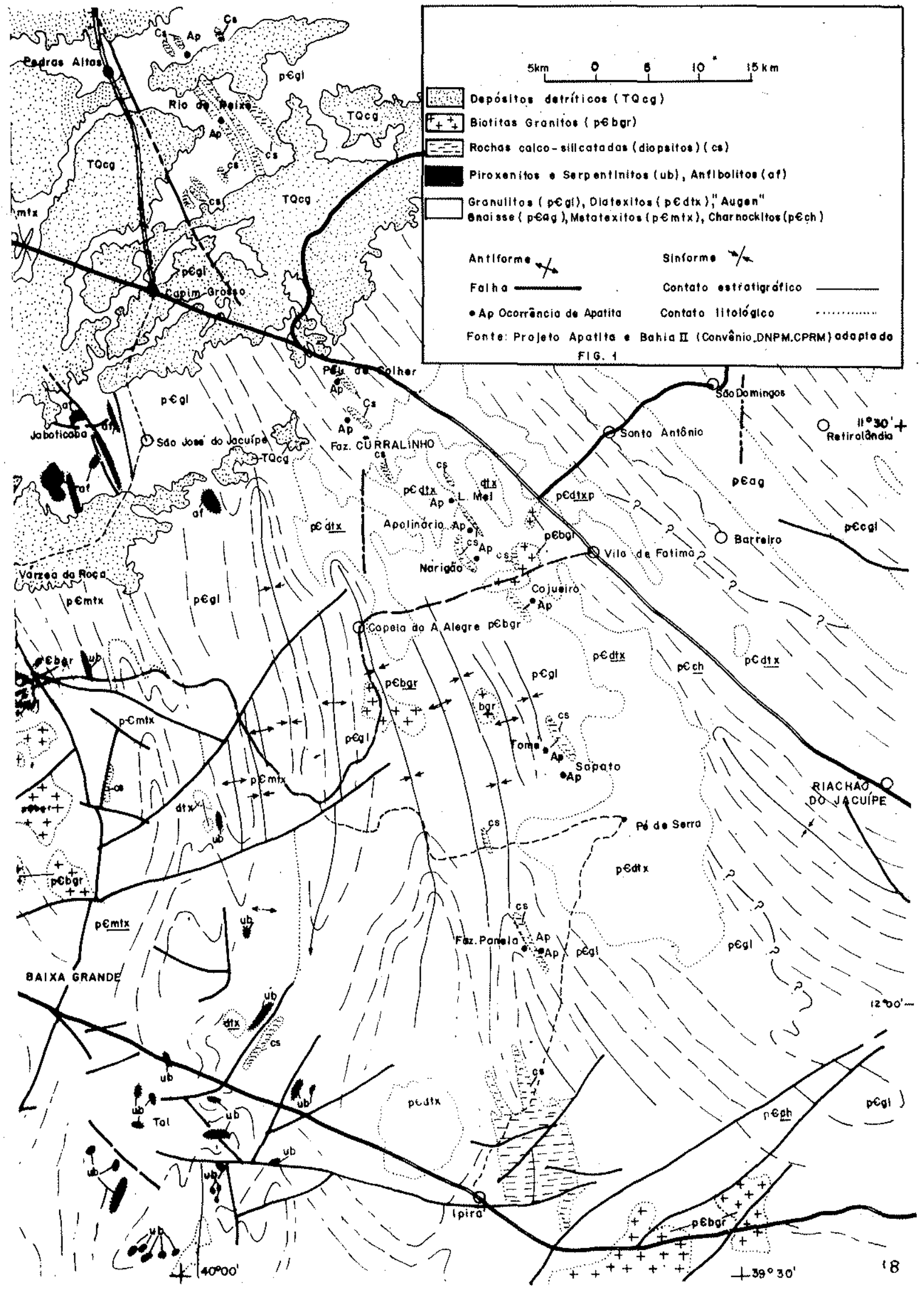

Figura·1 - Mapa geológico da área de Riachão do Jacuípe (BA) 
roxênio, microclina, biotita e hornblenda são os minerais mais comuns dessas rochas.

Os diatexitos ocorrem intimamente associados aos granulitos e aos charnockitos ou em suas zonas de contato. Os tipos ricos em piroxênio são de granulação média-grosseira, com estruturas migmatíticas, nebulíticas e schlieren, podendo conter enclaves escuros de composição gabróica. Os tipos sem piroxênio formam contatos bruscos com os granulitos, possuem coloração de rósea a cinzenta, granulação média e foliação difusa. Mineralogicamente, são constituídos por microclina, quartzo, plagioclásio e biotita, tendo como acessórios zircão, apatita e epidoto. Os geólogos do Projeto Bahia II (DNPM-CPRM) consideraram a ausência de produtos refratários, que deveriam ser abundantes caso essas rochas fossem originadas in situ por processos palingenéti$\cos$, a partir de uma seqüência rica localmente em intercalações calcossilicáticas, como evidências de uma proveniência mais afim com processos para-autóctones. Quartzitos, rochas calcossilicáticas (diopsiditos) e anfibolitos estão associados aos granulitos, principalmente na porção central do mapa geológico (área de Riachão de Jacuípe), constituindo corpos concordantes com a foliação regional noroeste-sudeste. Estas dispõem-se em extensões com larguras individuais em torno de 150 $\mathrm{m}$ e somatórios de segmentos longitudinais de centenas de quilômetros.

Os biotita granitos aparecem como pequenas ilhas isoladas nos granulitos e são considerados como intrusivos.

\section{COMPLEXO METAMÓRFICO-MIGMATÍTICO -} PRÉ-CAMBRIANO Rochas constituintes desses complexos estão em geral bordejando o Complexo Granulítico. Nas áreas próximas a Baixa Grande e Mairi ocorrem migmatitos estromatolíticos da fácies anfibolito. O paleossoma é em geral a biotita e/ou hornblenda, formando bandas escuras contrastantes com o neossoma de composição granítica.

$\mathrm{Na}$ área em apreço são muito freqüentes as intercalaçōes de anfibolito e rara a presença de calcossilicáticas. Corpos ultrabásicos (serpentinitos) ocorrem em concordância com os metatexitos.

Os corpos graníticos a biotita e raramente a hornblenda apresentam intercalações intrusivas nas rochas metatexíticas, constituindo grandes extensões de áreas aflorantes.

\section{SEDIMENTOS TERCIARIOS São representados} por um nível conglomerático basal, com seixos bem arredondados de quartzo, dentro de uma matriz arenosa, e uma parte superior, areno-argilosa, em geral mal selecionada. Expōem-se em grandes coberturas inconsolidadas, denominadas Formação Capim Grosso, sobre as rochas dos complexos pré-cambrianos anteriormente referidos.

\section{DISTRIBUIÇÃO E CONTROLES DAS MINERALI- ZAÇÕES DE APATITA O condicionamento das mineralizações de apatita, por meio de um perfeito con- trole litológico - diopsiditos e pegmatitos de compo- sição sienítica - , foi comprovado em todas as ocorrências da Área Riachão de Jacuípe, na faixa com- preendida entre Ipirá e Pedras Altas.}

Esta constatação eliminou a hipótese da formação da apatita, a partir unicamente de pegmatitos, uma vez que não foram encontradas ocorrências associadas a outras unidades litológicas que não estivessem sob a influência de rochas piroxênicas (diopsiditos).

A interação de dois processos, para a formação dos jazimentos de apatita, parece provável:

l) Sedimentos de natureza predominantemente calcopelítica sofreram açós metamórficas, resultando em rochas essencialmente de composição, calco-magnesiana. A presença de calcita, tremolita'e epídoto nas rochas piroxênicas sugere essa possibilidade. Devido ao aumento de temperatura, a tremolita torna-se instável, disto resultando a transformação de parte da mesma em diopsídio. É possível que a quantidade original de magnésio tenha sido inferior à de cálcio, caso contrárío teria resultado na formação de maior quantidade, provavelmente, de forsterita.

II) Ações metassomáticas posteriores, com enriquecimento em fósforo, flúor e cloro, relacionados a uma manifestação pegmalítica de composição sienítica, infiltram-se em zonas fraturadas nos diopsiditos, digerindo-os em parte e formando concentrações "remobilizadas" de apatita.

Os trabalhos executados pela UFBA (Oliveira, 1976), na área da Serra das Panelas em mármores e diopsiditos por análises petrográficas e químicas, isotópicas de estrôncio, carbono e oxigênio, além de determinações geocronológicas, evidenciaram os seguintes aspectos: $a$ ) os pegmatitos alcalinos sieníticos foram introduzidos nas calcossilicáticas sendo responsáveis pela formação de apatita bem como pela migmatização das rochas de composição granítica no metamorfismo a altura da fácies anfibolítica dos mármores, diopsiditos e biotitagrafita xistos; $b$ ) as idades encontradas são do metamorfismo transamazônico, sendo essas rochas polimetamórficas, cujo metamorfismo inicial atingiu a fácies granulítica, de idade arqueana, confirmada pelos valores de ${ }^{18} \mathrm{O}$, os quais conferem aos mármores idade absoluta em torno de $2500 \mathrm{~m} . \mathrm{a}$; $c$ ) pelos dados mineralógicos poder-se-ia interpretar que os mármores são carbonatitos; e $d$ ) por elementos petroquímicos e geoquímica de isótopos ${ }^{13} \mathrm{C}$ e ${ }^{18} \mathrm{O}$, chegou-se à conclusão de que os mármores e os diopsiditos são derivados de carbonatos marinhos antigos enquanto a isotropia do $\mathrm{Sr}$ tirou a possibilidade de as citadas rochas serem carbonatitos. Uma origem híbrida para estas rochas, em que o grupo dos lantanídeos provém de fonte ígnea e o dióxido de carbono, por remobilização de rochas carbonáticas antigas, é a gênese mais provável admitida pela referida autora.

Os diopsiditos identificados dispõem-se em faixas com larguras variáveis entre 50 a $150 \mathrm{~m}$, sempre em concordância com a direção regional dos granolitos, gnaisses e migmatitos encaixantes. Individualmente, essas faixas têm comportamento diverso. Algumas vezes, restringem-se a poucos metros de comprimento, dispondose descontinuamente em corpos alinhados.

Com base nos estudos de mapeamentos regionais e de detalhe, conseguiu-se definir quatro áreas merecedoras de uma avaliação quantitativa das reservas de apatita do tipo "remobilizado": Rio do Peixe, Lagoa do Mel, Apolinário e Panela. 


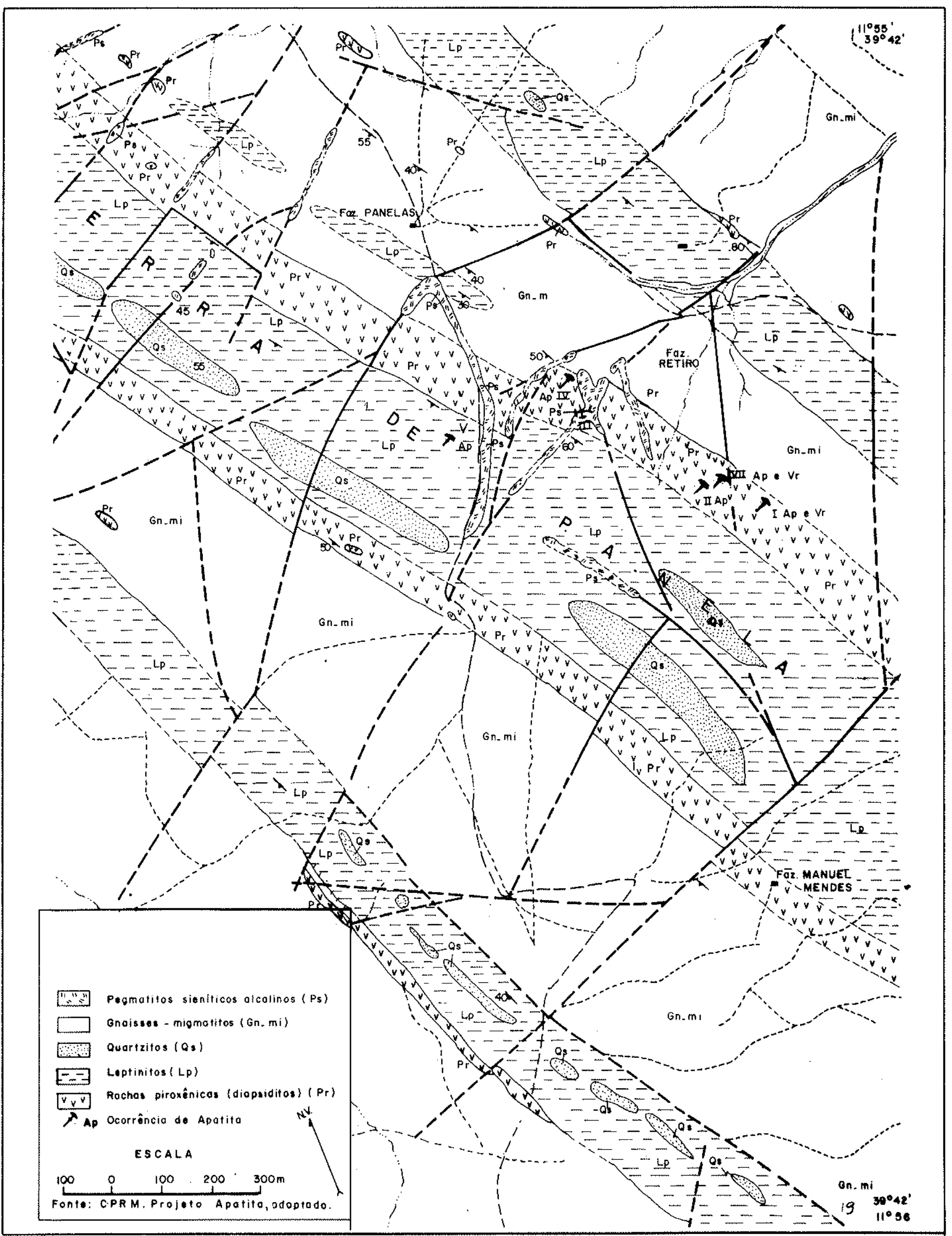

Figura 2 - Mapa geológico da área da Fazenda Panela 
As demais ocorrências catalogadas não apresentaram elementos motivadores para uma apreciação econômica significativa, tais as limitaçðes geométricas exibidas, sem uma palpável continuidade e com uma extrema variação lateral.

Diretrizes foram adotadas visando a determinar o potencial econômico das ocorrências mais promissoras, objetivando paralelamente reunir elementos comparativos para outras ocorrências, de forma semelhante mineralizadas. Trabalhos de mapeamento geológico, em escalas de 1:10000 e 1:200, prospecção cintilométrica e por escavações foram desenvolvidos nas diversas fases do Projeto Apatita. Cerca de $2000 \mathrm{~m}^{3}$ de material foram desmontados em etapas distintas dos estudos, em especial aqueles que objetivaram estimar as reservas dos jazimentos.

Considerou-se para os veios, para as lentes e para os bolsões das áreas anteriormente citadas uma persistência do minério em profundidade da ordem de 5 a $10 \mathrm{~m}$ em função de suas extensões longitudinais e laterais: Para a área de Rio do Peixe, utilizou-se uma profundidade de $11 \mathrm{~m}$ constatada em um dos poços realizados.

$\mathrm{O}$ teor médio em $\mathrm{P}_{2} \mathrm{O}_{5}$ foi estabelecido em $40 \%$.

Com os elementos mencionados, procedeu-se aos cálculos estimativos das reservas nas ocorrências mais promissoras, obtendo-se os seguintes valores:

Rio do Peixe ...................................2 $048 \mathrm{t}$

Lagoa do Mel ........................................915 t

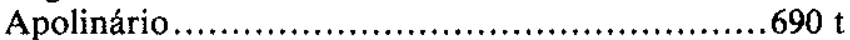

Panela ................................................ $113 \mathrm{t}$

Desprezando-se o fato de que parte dessas concentrações já foi superficialmente mineradas, tem-se uma reserva total estimada em $3766 \mathrm{t}$, para os quatro depósitos anteriormente mencionados.

Levando-se em conta que foi registrado um total de cinqüenta ocorrências (incluindo ocorrências insignificantes para um áproveitamento econômico) na área do Projeto e analisando-se, empiricamente, seu potencial quantitativo, cóm a finalidade única de estabelecer uma ordem de grandeza, constatou-se que, se a reserva das sete maiores ocorrências não atingiu $5000 \mathrm{t}$, dificilmente se alcançaria, para todos os jazimentos remobilizados estudados, um total de $10000 \mathrm{t}$ na profundidade pesquisada.

\section{DESCRIÇÃO DAS OCORRENCIAS}

\section{ÁREA DE PANELA A mineralização de apatita} tem uma distribuição horizontal razoável na encosta este da Serra de Panela. No entanto, não constitui um corpo mineralizado de grande extensão e continuidade, restringindo-se a pequenas zonas de limitadas dimensões.

Os depósitos, considerados isoladamente, são extremamente variáveis horizontal e verticalmente, apresentando-se em forma de "bolsoes", inseridos nas zonas de influência da rocha piroxênica (Fig. 2).

No "bolsão" mais promissor, indicado no mapa geológico da área como ocorrência VII, a reserva estimada não ultrapassa os limites de $53 \mathrm{t}$ de apatita, a uma profundidade média de $3 \mathrm{~m}$.
Para os outros seis "bolsoes", estima-se uma reserva total de $60 \mathrm{t}$, sendo que três deles apresentam quantidades insignificantes de apatita. Notadamente, nos outros três depósitos, a apatita está disposta em pequenos cristais, dispersamente distribuídos em massa de calcedônia/opala, o que dificulta em muito sua extração.

Nas faixas de rochas piroxênicas, a oeste da Serra de Panela, não foram localizadas mineralizações; este fato talvez esteja relacionado à ausência de pegmatito, outro elemento participante na formação de apatita do tipo "remobilizado".

As associações mineralógicas de apatita são bem definidas, destacando-se calcita e vermiculita. Esta última, em certos locais, constitui a maior parte dos minerais associados. Surgem também, freqüentemente, escapolita e opala-calcedônia.

Na ocorrência $V$, grande quantidade de calcita cristalizada encontra-se associada à apatita.

É conveniente destacar que pequenas lentes de material grafitoso são observadas na área de influência da rocha gnáissica, principalmente no contato leste com as rochas piroxênicas. Essas lentes são compostas de quartzo granular, material argiloso e palhetas de grafita, finamente estiradas e dispostas paralelamente em bandas finas e nitidamente limitadas. A grafita constitui cerca de $20 \%$ do total da rocha. Constatou-se pela análise química um teor em carbono fixo de $11,2 \%$.

Os falhamentos transversais, segundo a direção $\mathrm{N} 50^{\circ}-80^{\circ} \mathrm{E}$, estão relacionados à fase pegmatítica sienítica que se introduziu na rocha piroxênica rica em diopsídio, tornando-se assim um controle importante na localização dos depósitos.

ÁREA DE RIO DO PEIXE Os estudos de detalhe, desenvolvidos na área de Rio do Peixe, vieram ratificar a previsão, que apontava esta ocorrência como a mais promissora da área (Fig. 3).

As faixas de rochas piroxênicas, em número de cinco, mostram fortes indícios de mineralizações de apatita em pelo menos três locais. Com a evolução dos trabalhos de mapeamento geológico, em escala 1:10 000 e de prospecção por escavações, constatou-se que em apenas um local, compreendido em uma área de $19000 \mathrm{~m}^{2}$, existiam mineralizaçóes que ofereciam evidências de possuir uma maior extensão.

Em trabalhos posteriores de mapeamento de detalhe, acompanhados de uma minuciosa prospecção por escavações, obtiveram-se dados que possibilitáram o dimensionamento dos depósitos.

Observou-se, junto à apatita, a constante presença de pegmatitos alcalinos cortando rochas piroxênicas.

Localmente, na área que engloba as ocorrências IV, V e VI, destacam-se dois "bolsões" de apatita individualizados e distanciados cerca de $40 \mathrm{~m}$ um do outro. Ambos os corpos mineralizados mostram a direção preferencial $N 5^{\circ} \mathrm{W}$ e estão incluídos inteiramente em uma zona de influência de rocha piroxênica, afetadas pelos pegmatitos, considerados como agentes mineralizadores.

No bolsão localizado a este da área, assinalado no mapa com o número $\mathrm{V}$, escavações mostraram mineralização até a profundidade de $6 \cdot \mathrm{m}$, com uma concentração acima de $25 \%$. Esta concentração se mantém até 


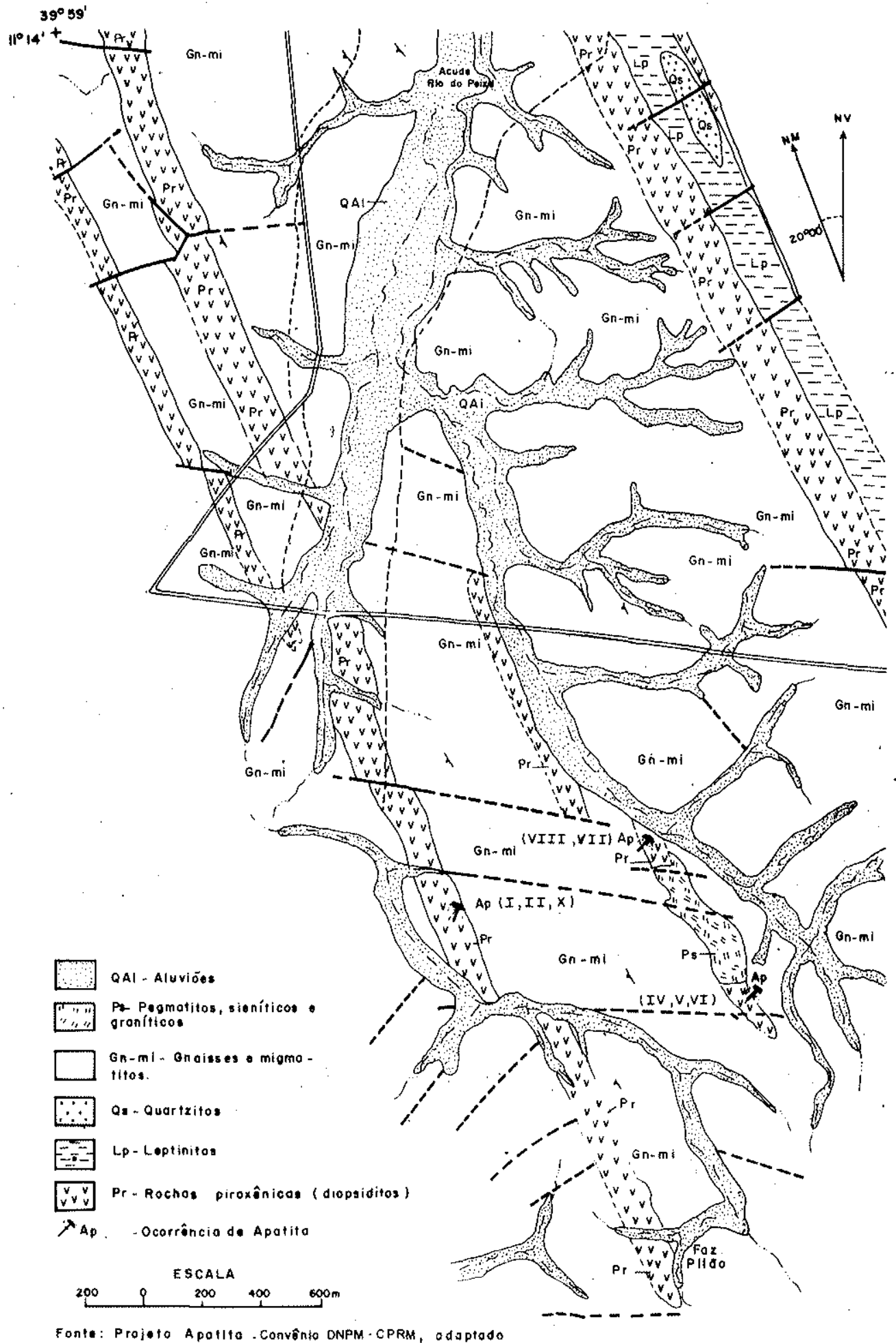

Figura 3 - Mapa geológico da área de Rio do Peixe 
a largura de $3 \mathrm{~m}$ por $10 \mathrm{~m}$ de comprimento. Após esses limites, a apatita torna-se mais dispersa, atingindo no máximo $25 \%$ de concentração e estendem-se até $60 \mathrm{~m}$ de comprimento, com uma largura máxima de $4 \mathrm{~m}$, passando bruscamente para a rocha estéril.

A oeste da área anteriormente citada, o bolsão IV de igual comportamento, segundo a mesma direção, mostra na escavação principal apatita até $11 \mathrm{~m}$ de profundidade. A partir daí, até alcançar $13 \mathrm{~m}$, existe um empobrecimento acentuado com aparecimento de uma zona algo migmatizada, composta essencialmente de quartzo, feldspato, biotita, epídoto e magnetita.

A concentração acima de $25 \%$ de apatita com $5 \mathrm{~m}$ de comprimento na direção nortem-sul, à largura de $1 \mathrm{~m}$, passa gradativamente para uma concentração mais pobre (abaixo de $25 \%$ ), alcançando $32 \mathrm{~m}$ de comprimento e no máximo $3 \mathrm{~m}$ de largura.

Dentro da faixa da rocha piroxênica, dispersamente distribuídos, aparecem outros bolsões de pequenas dimensões, alcançando em média $4 \mathrm{~m}$ de comprimento por meio metro de largura, com concentração menor que $25 \%$ de apatita.

As análises químicas da apatita dessas ocorrências revelaram teores de $\mathrm{P}_{2} \mathrm{O}_{5}$ acima de $40 \%, \mathrm{Fe}_{2} \mathrm{O}_{3}$ inferiores a $1 \%$ e traços de óxido de alumínio, demonstrando assim sua alta qualidade.

Além das mineralizações mencionadas, merece citação o local 1 , conhecido como ocorrência de Umbuzeiro. Nesta, a apatita aparece associada à rocha piroxênica e a pegmatitos de composição sienítica. A continuidade dos trabalhos de escavação confirmou esta previsão, mostrando a apatita em finas camadas envolvendo a rocha piroxênica, com uma concentração menor que $10 \%$, e distribuida dispersamente.

Em geral, as relações paragenéticas das mineralizações em Rio do Peixe, coincidem com as das demais ocorrências, destacando-se a presença de escapolita (meionita), biotita/vermiculita e opala-calcedônia.

Nas proximidades da ocorrência VI, constatou-se a existência de maior quantidade de biotita/vermiculita associada à apatita, entretanto em grandeza insignificante, comparativamente às ocorrências de Panela-Retiro e Apolinário.

As mineralizações de apatita, anotadas no mapa geológico com os números VI, VIl e VIII, mostram, analogamente, as mesmas relações com as encaixantes, possuindo contudo uma distribuição sem importância do ponto de vista econômico.

Em razão da situação das escavações IV e VII, inclusas e obedecendo direcionalmente a uma faixa de domínio de rocha piroxênica, acrescido pelo fato de ambas mostrarem mineralizaçōes em apatita, levantou-se a hipótese de uma continuidade entre essas duas ocorrências. Após o desenvolvimento de estudos detalhados de prospecção por escavações, concluiu-se a esterilidade desta zona intermediária, constituída exclusivamente de pegmatitos e gnaisses, mostrando às vezes a rocha piroxênica parcialmerite digerida pelos pegmatitos.

No restante da área mapeada, $10 \mathrm{~km}^{2}$ em escala 1:10 000, foram executados cerca de cinqüenta poços com a finalidade de obter subsídios para o mapeamento e, concomitantemente, verificar a possibilidade de se encontrarem novas ocorrências.

Durante esses trabalhos, foram descobertas novas ocorrências, guardando sempre as mesmas relaçóes que as anteriores, no 'entanto com dimensões bastante limitadas.

Restritas ocorrências aparecem dispersamente associadas às rochas piroxênicas de Rio do Peixe, em zonas fora do alcance da área com recobrimento aerofotogramétrico.

ÁREA TOMÉ-SAPATO Distanciadas uma da outra, a aproximadamente $3 \mathrm{~km}$, essas ocorrências estão incluídas em zonas que sofreram um acentuado processo de granitização, limitando, deste modo, a possibilidade de extensas mineralizações. Observa-se uma evidente associação de pegmatitos, em sua maior parte apresentando uma composição essencialmente granítica (praticamente quartzo e feldspato), com a rocha piroxênica, esta última em menor quantidade.

A apatita, em cristais de 2 e $5 \mathrm{~cm}$ de comprimento, apresenta, excepcionalmente, em relação às demais ocorrências, uma coloração verde-esmeralda e distribuise sob a forma de veios; às vezes, a apatia forma com o pegmatito de composição sienítica e a rocha piroxênica uma massa irregular.

Entre os minerais associados, destacam-se microclina, albita, anfibólio e opala/calcedônia (algumas vezes formando drusas), sendo que a presença deste último, envolvendo e cortando os cristais de apatita, atesta uma atividade tardia de silicificação.

Na ocorrência de Tomé, além dos minerais citados, destacam-se a presença de calcita de coloração branca e rosa, e algum epídoto.

Diversos poços e trincheiras foram desenvolvidos nessas ocorrências e uma quantidade inexpressiva de apatita, para um aproveitamento econômico-industrial, foi extraida.

ÁREA DE APOLINÁRIO Trabalhos de garimpagem, executados por particulares no bolsão principal, com o propósito de extrair economicamente a vermiculita associada, expuseram a zona mineralizada em apatita. Parageneticamente, estão presentes: escapolita, epídoto e opala/calcedônia.

Novas escavações foram realizadas com o intuito de definir esse depósito de apatita, constatando-se então a limitada extensão da mineralização.

Duas faixas de rochas piroxênicas, cortadas por veios pegmatíticos de composição essencialmente quartzo-feldspática, estão separadas por uma zona de maior influência de rocha pegmatítica.

Uma concentração de apatita, em torno de $30 \%$, com $14 \mathrm{~m}$ de comprimento, de 6 a $8 \mathrm{~m}$ de largura e $10 \mathrm{~m}$ de profundidade, constitui-se na principal zona mineralizada, em Apolinário. Além desta, existem pequenos bolsões e veios, tendo o maior deles $150 \mathrm{~m}^{3}$ de volume, com uma concentração, aproximada, de $20 \%$ em apatita. Nos extremos da área existem extensos afloramentos de rochas migmatíticas.

ÁREA CABACEIRA-MANDACARU Ambas as ocorrências pertencem à mesma faixa de rocha piroxêni- 
ca e estão distanciadas aproximadamente $500 \mathrm{~m}$ uma da outra.

A mineralização de apatita aparece em pequenos bolsões e disseminada na rocha piroxênica, cortada por veios pegmatíticos.

Nas escavações existentes, apenas duas delas mostram apatita encaixada em rochas piroxênicas. Uma delas, com $8 \mathrm{~m}$ de comprimento por 1,50 $\mathrm{m}$ de largura, denuncia uma maior quantidade de rocha pegmatítica em relação à rocha piroxênica.

Nela, a apatita, em distribuição irregular, não totaliza sequer $10 \mathrm{~kg}$ e corresponde a uma desmonte de cerca de $30 \mathrm{t}$.

Opala de coloração vermelha e amarelada estão presentes.

Outra escavação que merece referência é a que apresenta calcita, com inclusão de especularita. Esta calcita, por vezes, está sob um solo escuro e não foi verificada apatita associada a ela.

A associação paragenétical da apatita, com biotita/vermiculita e escapolita, aparece e quantidade discreta.

ÁREA LAGOA DO MEL Foram desenvolvidos, na área desta ocorrência, trabalhos de detalhe visando a obter dados para uma estimativa das reservas de apatita.

Verifłcou-se uma menor distribuição de apatita, comparativamente à de Rio do Peixe, guardando entretanto o mesmo comportamento geológico.

Constatou-se a presença de três faixas de rochas piroxênicas, a maior delas com $60 \mathrm{~m}$ de largura, com direção geral $\mathrm{N} 30^{\circ} \mathrm{W}$ e separadas por zonas pegmatíticas.

$\mathrm{Na}$ parte sudeste da área, foram executadas três grandes trincheiras, que expuseram veios de apatita as. sociados a pequenas quantidades de escapolita e biotita/vermiculita, rocha piroxênica e pegmatitos de composição quartzo-feldspática.

As zonas mineralizadas mostram concentrações de apatita com teor variando de $25 \%$ a $30 \%$ e-largura média de $1,50 \mathrm{~m}$.

Fraturamentos, com direções principais de $\mathrm{N} 70^{\circ} \mathrm{W}$ e $\mathrm{N} 75^{\circ} \mathrm{E}$, e mergulhos, respectivamente, para sudoeste e noroeste em torno de $60^{\circ}$, sấo característicos na área.

A escavação principal expõe um bolsão ramificado de apatita com uma zona de influência de $20 \mathrm{~m}$ de comprimento por $10 \mathrm{~m}$ de largura, escavado até a profundidade de $3,50 \mathrm{~m}$. A direção preferencial, localmente, da mineralização é de $\mathrm{N} 60^{\circ} \mathrm{E}$.

As demais zonas mineralizadas variam em extensão, tendo a maior delas $16 \mathrm{~m}$ de comprimento por $6 \mathrm{~m}$ de largura e a menor, $6 \mathrm{~m}$ por $60 \mathrm{~cm}$, estando todas dispostas, de preferência, segundo a direção geral de $\mathrm{N} 35^{\circ}-40^{\circ} \mathrm{W}$

ÁREA PAU DE COLHER-CURRALINHO Duas ocorrências, próximas à localidade de Pau de Colher, uma na Fazenda Queimada da Prensa e outra na Fazenda Curralinho, serão aqui descritas em conjunto. A distância entre a ocorrência do extremo norte (Pau de Colher) e a situada mais ao sul (Curralinho) é de cerca de $4 \mathrm{~km}$.
As três primeiras citadas possuem escavações exibindo rocha piroxênica foliada segundo a direção $\mathrm{N} 30^{\circ} \mathrm{W}$, mergulhando $50^{\circ}-60^{\circ}$ para oeste, cortada por pegmatitos de composição sienítica. A apatita aparece em quantidades quase acessórias. Biotita/vermiculita dispõemse sob a forma de veios, com direção $\mathrm{N} 10^{\circ} \mathrm{W}$ e espessura de até $30 \mathrm{~cm}$.

Particularmente, na ocorrência de Queimada da Prensa, existe uma maior exposição de vermiculita. Testes preliminares de campo, neste material, mostraram expansibilidade térmica de até treze vezes, o que torna possível seu aproveitamento econômico a depender de testes termodiferenciais em laboratórios, além de trabalhos de detalhe.

Em Curralinho, em superfície e pelas exposições obtidas por escavações, constataram-se as mesmas relações litológicas das demais ocorrências. A apatita está distribuida dispersamente e em quantidades insignificantes, guardando sempre um comportamento paragenético análogo. Convém ressaltar que, nas proximidades dessas mineralizações, existem grandes extensões de áreas migmatizadas.

ÁREA DE PEDRAS ALTAS Situada no extremo norte da área do Projeto, esta ocorrência foi objeto de estudo detalhado, tendo sido executado o mapeamento geológico, cobrindo uma extensão de 80 ha e englobando as mineralizações de apatita.

Regionalmente, predomina a rocha migmática, essencialmente heterogênea, tendo os tipos diadsíticos e agmatíticos como os mais identificáveis. Sua composição consiste principalmente em grãos de quartzo, cristais de microclina, plagioclásio, biotita e anfibólio em menor quantidade. As rochas piroxênicas, com coloração cinza-esverdeada e contendo as minerações de apatita, dispõem-se em faixas paralelas, seguindo o trend regional.

A apatita, em cristais de até $5 \mathrm{~cm}$ de comprimento, distribui-se em veios e pequenos bolsões, de preferência em uma única faixa de rocha piroxênica e em quantidades acessórias ao longo das demais faixas de idêntica composição.

Pegmatitos de composição quartzo-feldspática, com direção $\mathrm{N} 70^{\circ}-80^{\circ} \mathrm{W}$, aparecem cortando os outros tipos litológicos. Um veio pegmatítico, alcançando $70 \mathrm{~m}$ de largura e mais de $500 \mathrm{~m}$ de comprimento, aparece cortando discordantemente as outras unidades litológicas.

Rochas leptiníticas, às vezes guardando restos de material quartzítico dentro delas, margeiam as faixas de rochas piroxênicas. Em certos trechos, esses quartzitos ocorrem sob a forma de lentes de até $1 \mathrm{~m}$ de largura no interior das zonas de influência da rocha piroxênica. Nessas condições, uma quantidade apreciável de epídoto é observada, associado a grãos dispersos de apatita.

Nas zonas mineralizadas, existem três grandes escavações, uma delas atingindo $15 \mathrm{~m}$ de profundidade, tendo sido extraída, há anos, relativamente, pouca quantidade de apatita.

No desmonte da rocha piroxênica, encontram-se quantidades acessórias de apatita.

Outras pequenas ocorrências, localizadas na Fazenda Santana, próxima à localidade de Tomé, Fazenda Extrema, próxima à ocorrência de Narigão e dá Fazen- 
da Pedra Branca, situada a noroeste de Panela, não justificaram maiores considerações em razão das acanhadas distribuições em apatita e da similitude que guardam com as ocorrências já descritas.

\section{CONCLUSÕES E RECOMENDAÇÕES As ocorrên-} cias de apatita estão distribuídas segundo a direção $\mathrm{N} 25^{\circ}-30^{\circ} \mathrm{W}$ e estão sujeitas a um marcante controle litológico: rochas piroxênicas diopsídicas e pegmatitos de composição sienítica associados com falhamentos nos tipos "remobilizados".

A associação paragenética de apatita, vermiculita, opala, calcedônia e escapolita é freqüentemente notada.

Um solo argiloso de coloração cinza-escuro denuncia a presença das rochas piroxênicas e pode servir, indiretamente, como guia na descoberta de novas ocorrências de apatita.

Admite-se a interação de dois processos para a formação de mineralizações de apatita. As rochas diopsídicas originam-se a partir de sedimentos de natureza calco-pelítica. Ações metassomáticas posteriores, ricas em fósforo, flúor e cloro, ligadas a uma manifestação pegmatítica de composição sienítica, infiltraram-se nas rochas piroxênicas, digerindo-as parcialmente e formando em zonas de composição mais cálcica concentrações de apatita.

A relativa estabilidade do diopsídio e a restrita influência do pegmatito sienítico, considerado como um dos: agentes mineralizadores, podem justificar a ausência de grandes exposições de apatita, para o tipo remobilizado, nas profundidades investigadas.
Verificou-se por análises químicas o excelente valor qualitativo da apatita para fins industriais. Teores de $\mathrm{P}_{2} \mathrm{O}_{5}$ acima de $39 \%$, traços de óxido de alumínio e baixos teores de óxido de ferro.

Elementos de terras raras aparecem intimamente relacionadas às ocorrências de apatita. Leituras cintilométricas realizadas no interior de escavações acusaram valores de até $5000 \mathrm{cps}$.

A presença de monazita nas zonas de influência dos pegmatitos mascararam, provavelmente, os valores radiométricos de uma possível mineralização de apatita, localizada em maior profundidade.

Os parâmetros indicados para a localização de novas ocorrências de apatita são válidos para a descoberta de ocorrências de vermiculita de idêntico condicionamento geológico.

Disseminações de apatita nas rochas diopsídicas devem ser estudadas objetivando definir sua potencialidade econômica, evocando-se uma origem a partir de uma antiga seqüência sedimentar pelito-carbonática. Sugere$\mathrm{se}$, entre outras, a área de aproximadamente $120 \mathrm{~km}^{2}$, localizada nas proximidades nordeste de Ipirá, como o alvo prioritário para esse tipo de investigação.

Na região de Palobora, África do Sul (Coetzee, 1976), mais de 30 milhões de $t$ de rocha piroxênica fosfática com 7,5\% de $\mathrm{P}_{2} \mathrm{O}_{5}$, até 1972, haviami sido lavradas. Isso resultou na produção de 4,5 milhốes de t de concentrado de fosfato com $36,4 \%$ de $\mathrm{P}_{2} \mathrm{O}_{5}$, representando a principal matéria-prima para a produção de superfosfato. Conclui-se então que teores dessa ordem, se constatados em rochas piroxênicas (diopsiditos), poderão tornar econômicas mineralizações que envolvam idêntica ambiência geológica.

Quadro 1 - Análises petrográficas de rochas piroxênicas (em \%)

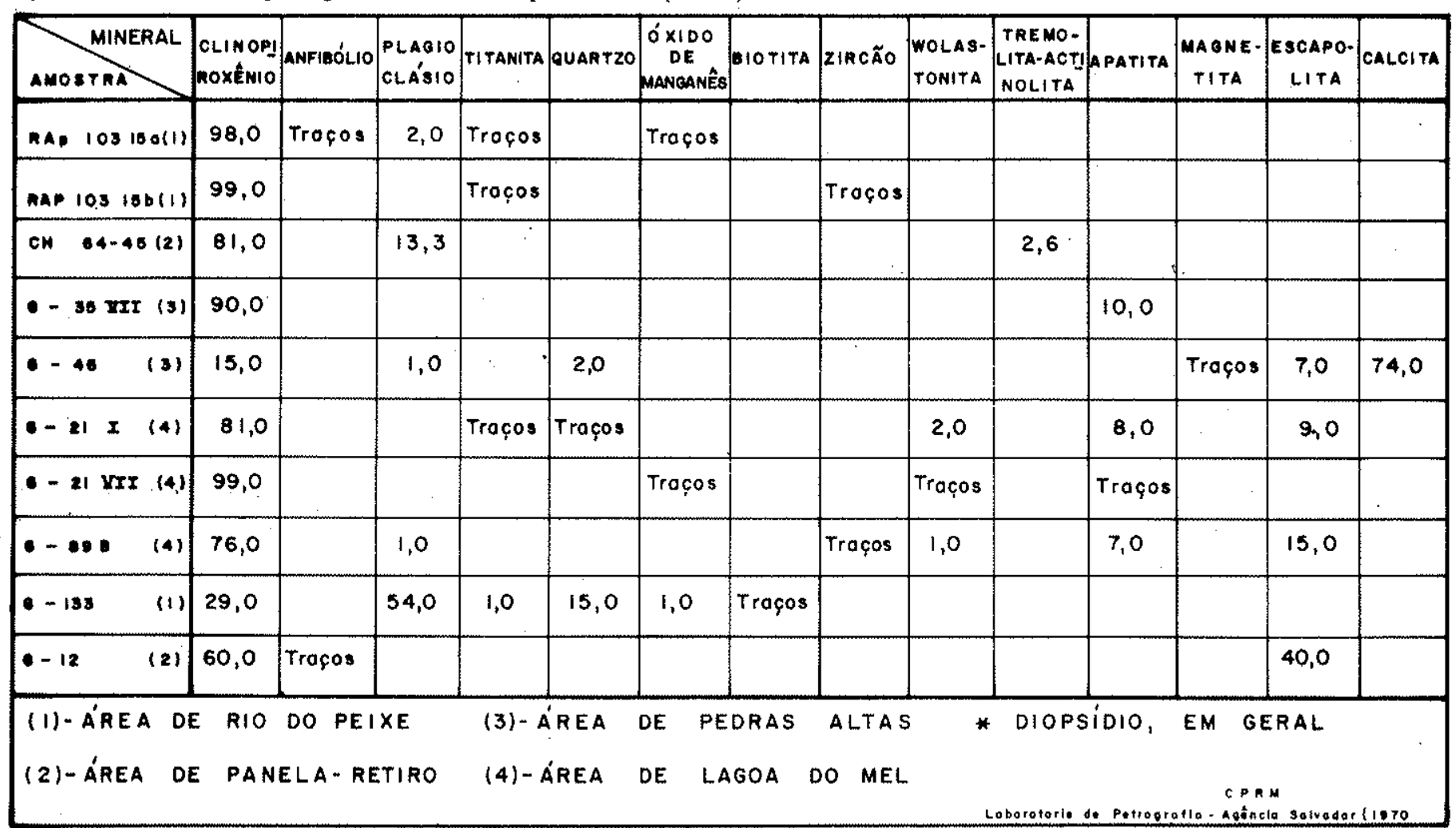


Quadro 2 - Análises quimicas de rochas piroxênicas (em \%)

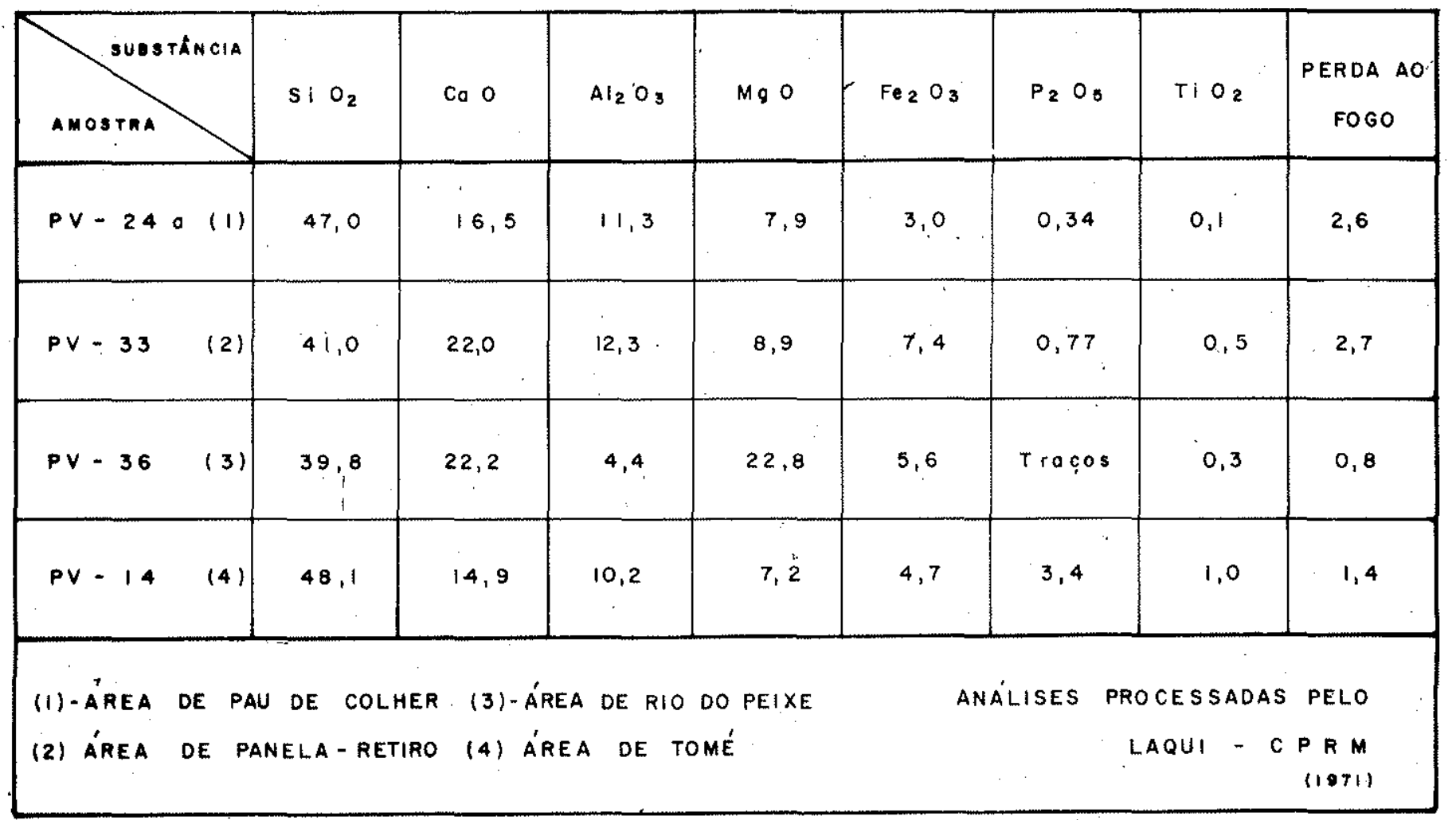

Quadro 3-Análises espectrográficas de apatita (semiquantitativas)

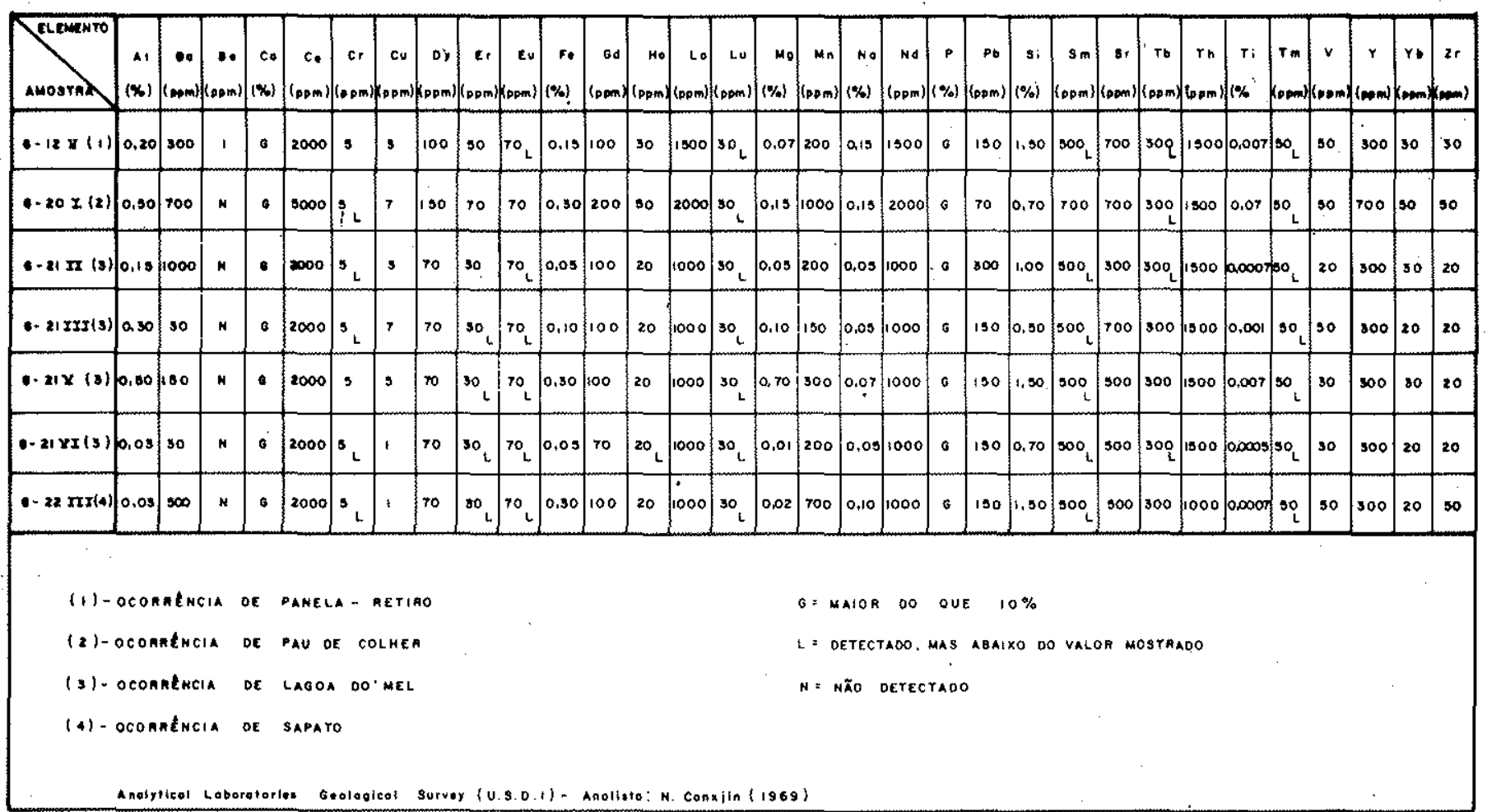


Quadro 4 - Análises químicas de apatita (em \%)

\begin{tabular}{|c|c|c|c|c|c|c|c|c|c|}
\hline AMOSTAA & $\mathrm{Al}_{2} \mathrm{O}_{3}$ & $\mathrm{CoO}$ & $\mathrm{Fe}_{2} \mathrm{O}_{3}$ & MoO & $\mathrm{P}_{2} \mathrm{O}_{5}$ & $\mathrm{~S}+\mathrm{O}_{2}$. & CLORETOS & FLUORETOS & PEROA AOFOGO \\
\hline$P V-21 \quad 111$ & Trogor & 50,8 & 1,4 & Troços & 40,5 & 1,7 & $0,4$. & 0,9 & 0,4 \\
\hline$P V \cdot 2: 0 \quad(1)$ & Trogos & 50,9 & 0,4 & Tragos & 40,8 & 1,1 & 0,5 & 1,0 & 0,3 \\
\hline$P V=1 B \quad(2)$ & Trogos & 51,1 & 0,3 & Trogos & 42,0 & 1,5 & 0,4 & 0,5 & 0,4 \\
\hline$p v-19 \quad(2) \mid$ & Trogos & 5,9 & 0,5 & Yrocos & 41,2 & 0,9 & 0,6 & 1,2 & 0,4 \\
\hline$P v-210(3)$ & Tragos & 51,5 & 0,4 & Traços & 41,2 & 1,0 & 0,6 & 1,1 & 0,4 \\
\hline$P V-30(4)$ & Tracos & 51,4 & 0,2 & TroģOB & 42,1 & 3,2 & 0,4 & 0,6 & 0,2 \\
\hline$P V-28 c(5)$ & Trogos & 50,1 & 0,4 & Trogos & 41,5 & 1,4 & 0,4 & 0,8 & 0,8 \\
\hline$P V-28 d(3)$ & Traco: & 50,1 & 0,3 & trocos & 41,1 & 1,8 & 0,4 & 0,8 & 0,8 \\
\hline$P V-270(6)$ & Troços & 50,5 & 0,3 & Troços & 41,9 & 0,9 & 0,4 & 0,8 & 0,4 \\
\hline$p V-27 c(6)$ & Tragos & 49,6 & 0,6 & Traços & 41,0 & 2,9 & 0,4 & 0,8 & 0,4 \\
\hline$P V-27 d(6)$ & Troços & 49,3 & 0,6 & T!O ६̧Os & 40,7 & 3,5 & 0,4 & 0,9 & $0,4$. \\
\hline$P V-27 \cdot|6|$ & Trogos & 49,6 & 0.4 & Trofos & 41,1 & 1,1 & 0.4 & 0,8 & 0,4 \\
\hline$P V=27+(6)$ & Trofor & 49,4 & 0,6 & Troşos & 41,1 & 1,6 & 0,4 & 0,9 & 0,3 \\
\hline$P V \cdot 13$ a $\{7\}$ & Traço: & 49,0 & 0,8 & $T: 0$ ço. & 39,1 & 6,7 & 0,4 & 1,0 & 0,3 \\
\hline$p v-140.181$ & Troços & 48,9 & 0,4 & Traços & $40: 1$ & 3,3 & 0,4 & 0,9 & 0,2 \\
\hline 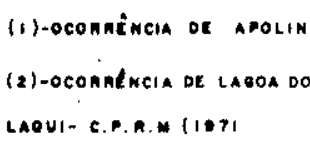 & MEL & 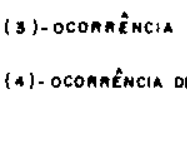 & $\begin{array}{l}\text { OE haAiGão } \\
\text { OE PANELA- RETIRO }\end{array}$ & 15 & $\begin{array}{l}\text { ORRÉNCHA OE } \\
\text { ORRÊNCIA OE }\end{array}$ & $\begin{array}{l}\text { PEORAS ALTAS } \\
\text { RIO OO PEIXE }\end{array}$ & $\begin{array}{l}(7)-000 \\
(a)-0<0\end{array}$ & $\begin{array}{l}\text { HÉNCIA DE SAR } \\
\text { AÉNCIA OE TOM }\end{array}$ & \\
\hline
\end{tabular}

\section{BIBLIOGRAFIA}

COETZEE, C.B. - 1976 - Mineral Resources of the Republic of South África.

NEVES, B.B. DE BRITO et al. - 1980 - "Evolução geocronológica do Precambriano do Estado da Bahia". In: Inda, H.A.V. e Duarte, F.B. "Geologia e Recurșos Minerais do Estado da Bahia; Textos Básicos'”. Salvador, SME/CPM. vol. 3. pp. 1-101.

NEVES, B.B.B. F FEITOSA, E.C. - 1969 - "Proposição e estudos geológicos preliminares da, 'Formação Capim Grosso"'. In: Congresso Brasileiro de Geologia, 23, Salvador, 1969. Resumos, SBG (Boletim especial, 1) p. 60.
OLIVEIRA, M.A.F.T. - 1976 - "Petrologia e Geoquimica das Mármores Calcossilicatadas, Ipirá, BA". Salvador, UFBA/Inst. Geociências, 104 pp. SEIXAS, S. et al. - 1975 - "Projeto Bahia II; Geologia das Folhas Itaberaba eserrinha, Relatório Final". Salvador, CPRM, vol. I.

Recebldo em 25 de Fevereiro de 1981. 